\title{
Evaluation of Serious Game User Experience: the Role of Emotions
}

\author{
Philippe Cohard \\ University of Montpellier, MRM, Montpellier, France \\ Labex Entreprendre, Institut Montpellier Management \\ philippe.cohard@umontpellier.fr \\ DOI: 10.34190/EJISE.19.22.2.005
}

\begin{abstract}
Serious games are slowly becoming a part of educational systems and corporate training facilities in lots of fields such as industry, health, management, etc. Despite this, the academic knowledge on these artefacts is still limited. The research reported in this paper examined emotional implications of serious games on the user experience. This correlational research observed the relationships between factors of serious gaming and emotions. Fifty students took part in the study. The participants used a serious game on the security of an Information System and answered a structured questionnaire. The data was analysed by Spearman's correlation. The results show that the quality components of the multimedia system and the quality of the content of the game are correlated with emotions, satisfaction and intention to use. Moreover, they show that emotions are correlated with satisfaction, learning and success of the serious game. Satisfaction and learning play a key role in these programs. If serious game training is to have some efficiency, a deeper understanding of the factors that lead to the success of these applications is required. These factors are all levers of control that affect the perception and emotions of the user. Understanding these mechanisms could eventually lead to more effective serious games.
\end{abstract}

Keywords: Serious game, emotion, learning, training, user experience, sentiment analysis

\section{Introduction}

Serious games are slowly becoming a part of educational systems and corporate training facilities in several fields such as industry, health, management, etc. According to Zyda (2005, p.30) "Applying games and simulations technology to non-entertainment domains results in serious games". The objectives of serious game and gamification of learning are the improvement of learning outcomes, but the processes to achieve such gains are different (Landers, 2014). Serious games affect learning directly by implementing training content. Gamification relies more on the pre-existing knowledge of the player. So based on different approaches (Zyda, 2005, Alvarez, 2007), the serious game can be defined as: the use of the playful and the means of video games for purposes that are not entertainment and the purpose of which is learning to change personal or social behaviour such as training, marketing, recruitment, etc.

Despite a keen interest in these systems, knowledge about serious games is still limited. A better understanding of the role played by the emotions in the success of the serious game could allow a more effective design of these programs. The existing systems development discussions that sometimes remains at a conventional level, could to be enriched from new dimensions. The emotional dimension, in particular, seems to play an important role and requires further investigation. This paper responds to an identified theoretical gap in respect of the implications of emotions in serious games (SGs). Based on this gap, the research question which this paper responds to is: What is the place of emotions in the experience of the user of serious game? The answer to this question will help to better understand the link between emotions and the use of serious games. The paper is structured as follows: first we present the theoretical framework and the review of the literature, then we explain the hypotheses, following a description of the implementation of the research and finally we discuss the results.

\section{Theoretical framework and literature review}

The literature review reveals several types of results and factors related to the serious games. We present these elements below: (1) results produced by the use of serious games, (2) factors related to the characteristics of the product "serious game", (3) factors of the organizational context, (4) individual factors of the user, and (5) emotional factors. Indeed, the literature converges towards the importance of emotions felt by users. 


\subsection{Results produced by the use of serious games}

The implications in the literature focuses on user satisfaction and learning improvement. User satisfaction is widely reported both on the use (Labonte-LeMoyne et al., 2017, Raybourn 2007, Zhang and Zwolinski 2015) and the acceptance of the serious game itself (Loerzel, Clochesy, and Geddie, 2018), even though requests for improvements or additional functions are expressed. The effectiveness of learning can be compared with other more traditional learning methods, either through knowledge assessment tests or by perceived learning. Moreover, Giard, Ecalle and Magnant (2013) noted that the effectiveness of serious games has not yet been fully proved, although the potential of engagement of the serious games. In their research Aydan et al. (2017) analysed a serious game for training to the ISO IEC 12207 standard. These authors showed that the training conditions have an influence on the results. Participants involved in serious game learning tended to have a more positive experience and better results than participants in the paper-based training group. Li et al (2017) indicate that the serious game is more effective for the procedural knowledge but that the two modalities (SG or paper) are equivalent for the factual knowledge. An increased engagement level is reported in the serious game training modality. Labonte-LeMoyne et al. (2017) showed in their study on 31 business school students that the serious game helps to improve the skills of learners on ERP. The ability of serious games to allow the acquisition of complex skills is in agreement with the work of Nadolski et al (2008). Learning can be individual but serious games can provide social learning too (Van der Wal et al. 2016). Finally, serious games can lead to knowledge creation: power trading competition (Ketter et al. 2016), optimization of refugee assistance (Estrada and Groen, 2017).

\subsection{Factors related to the serious game product characteristics}

These factors can be of two types: (1) related to the game, its multimedia implementation, and (2) the formative scenario related to the outcomes of training and learning.

The multimedia game design is related to the kind of game which has been implemented: simulation game (Van der Wal et al., 2016), puzzle games (Perez-Estrada, Groen and Ramirez-Marquez, 2017), point and click (Aydan et al. 2017, Li et al., 2017). The designers use technologies that make the interaction more or less rich and attractive (2D or 3D visual, sound, etc.). For example, Aydan et al. (2017) and Li et al. (2017) used a 3D engine (Unity). The more the multimedia quality of the interaction is rich, the more the complexity of performing the game increases. Therefore, there is a connection between learning objectives and needs in terms of multimedia, so as to satisfy the chosen game mode. In this design the product should be adapted to the cultural specificities of users as noted by Loerzel, Clochesy and Geddie, (2018) in their study. These properties of the game help to create emotions, especially through flow, which is an optimal experience (Csikszentmihalyi, 2008, Kirriemuir and McFarlane, 2004). Flow is explained in more detail, later on in this paper, in the section Emotional Factors.

The learning mode related to the use of the serious game (SG) can be taken into account upstream of the design, as soon as the training scenario is completed (Garris, Ahlers and Driskell, 2002). Kolb (2005) proposed an experiential learning cycle: first of the realization of a concrete experience, then a reflective observation, then an abstract conceptualization and finally an active experimentation. Bandura (1977) showed observation learning consisting of: (1) the attention phase (observe the model), (2) the retention phase (memorization), (3) the reproduction phase through concrete practice and (4) the reinforcement phase. These learning modes are widespread in serious games. Taking into account learning modes is important for serious games because improving multimedia quality cannot compensate a bad training scenario.

\subsection{Organizational context factors}

These factors appear either in the design phase or in the use phase in the form of conditions of use.

In the design phases, several authors explain the difficulty of developing such software, which may require multidisciplinary teams (Nadolski et al., 2008, Raybourn, 2007, Thompson et al., 2010) comprising script writers, graphic designers, 3D engine specialists, actors, sound specialists, and experts in the field. Teams and modes of achievement can be compared to those of film crews. However, current frameworks such as Scratch and Alice make it possible to overcome these organizational constraints, but do not provide the same results as those obtained with 3D engines. This is why several authors opted for 3D engines such as Unity3D (Aydan et al., 2017, Chou et al., 2018, Li et al., 2017, Matallaoui, Herzig and Zarnekow (2015). 
The conditions of use vary according to the context: use in the workplace (Li et al., 2017, Loerzel, Clochesy and Geddie, 2018) or use in training at the university (Aydan et al., 2017, Labonte-LeMoyne et al., 2017). The influence exercised by the environments where the serious game is used can be perceived through the remarks, the wishes for improvements or the requested changes of the professionals or students.

\subsection{Individual user's factors}

The literature shows presuppositions about the favourable reception of serious games by the younger generations. For example, for Giard and Magnant (2013), it appears that these populations, Digital Native, NetGeneration, will be very receptive to computer-assisted learning because they spend a lot of time playing video games. In the same approach Aydan et al. (2017) used their serious game with first year engineering students. If younger generations seem more aware of the use of video games, we should nerveless consider the interest of previous generations in the discovery and use of such artefacts. Loerzel, Clochesy and Geddie (2018) showed, in this respect, the use of a serious game for the training of the elderly suffering from their treatment with chemotherapy and cancer. However, this serious game seems adapted, because these people who tend to minimize the symptoms, received the application favourably. This is in line with the work of Cohard and Marciniak (2014) on the training of the staff of nursing homes.

The serious games design also makes it possible to adapt the type of learning to the learner. Experiential learning, based on Kolb (2005) or Bandura (1977) on social cognitive theory, is particularly used in serious games (Guillén-Nieto and Aleson-Carbonell, 2012, Labonte-LeMoyne et al. 2017, Van der Wal, of Kraker, Kroeze and Kirschner, 2016). Note that the profile of users of these games can be different, such as professionals, experts or beginners (Perez-Estrada, Groen and Ramirez-Marquez, 2017, Van der Wal et al., 2016, Zhang and Zwolinski, 2015). Finally, Erhel and Jamet (2013) identified intrinsic motivation and flow as important factors in learning through digital games. Flow can be achieved, in the game, through playfulness and concentration but also by the challenge it represents (Malone, 1981, Malone and Lepper, 1987) and the skill it requires (Bandura, 1977). So, taking into account user factors in the properties of the game helps to create emotions particularly through the flow.

\subsection{Emotional factors}

Two major streams of research coexist in the classification of emotions (Lichtlé and Plichon, 2014). The first one is called discrete perspective, the proponents of which claimed that the emotions are discrete, primary or basic and universal. The work of P. Ekman is representative of this school of thought (Ekman, 1992, 1999). The second one is the dimensional perspective, for which it was necessary to classify emotions in underlying dimensions. Russels' work, including his classification of affects, is representative of this school of thought (Feldman-Barrett and Russell 1998, Russell 1980).

Emotions are frequently mentioned in serious games, especially the joy of using it (Kirriemuir and McFarlane, 2004, Labonte-LeMoyne et al., 2017, Nadolski et al., 2008), but also sometimes anxiety with the fear of being evaluated (Cohard and Marciniak, 2014), which comes the notion of valence of positive or negative emotions. Emotions are often related to flow's experience. Flow is a psychological state of pleasure and satisfaction and a feeling of control associated with a high concentration of attention on a task (Csíkszentmihalyi, 1988). Flow is linked to a high level of commitment (Sherry, 2004). De Manzano et al. (2010) showed in a study of the physiological responses of 21 pianists that flow is related to physical changes, which among other things influence heart rate and respiration.

Others emotions than the flow (e.g.: fear, anger, etc.) can occur, or even disrupt the use of serious games or information systems in general. Indeed, emotions have an influence on behavior and cognition. Beaudry and Pinsonneault (2010) developed a framework that classifies emotions into four distinct types: challenge, success, loss and deterrence. This framework can be compared by some aspects to Russell's classification of affects (1980). These authors tested the direct and indirect relationships between four emotions (excitement, happiness, anger and anxiety) and the use of Information Technologies. The authors studied these relationships through a survey of 249 managers in the banking sector. Beaudry and Pinsonneault (2010) showed in their research: (1) that excitement is positively related to IT use through the task adaptation, and (2) that happiness is directly positively related to IT use, but that happiness is negatively associated with task adaptation. Indeed, Cohn et al. (2009) showed in their study of 89 students that positive emotions are a predictor of the ability to adapt to a changing environment called resilience of the Ego. Furthermore, Beaudry and Pinsonneault (2010) also showed (3) that anger is not directly related to IT use, but that it is positively 
related to the research of social support. Finally, these authors show that (4) anxiety is negatively related to the IT use, both directly and indirectly through psychological distancing. They pointed out that anxiety was also indirectly positively related to IT use by seeking social support, offsetting the negative effect.

The state of anger can be defined as a "universal transitory condition consisting of subjective feelings of anger", the intensity and duration of which vary (Spielberger et al., In Quinn, Rollock and Vrana, 2014, p.2). This state produces a physiological reaction that increases with the intensity of the subjective feelings of anger. The state of anger is a negative feeling, related to the non-satisfaction, boredom, frustration and disgust according to Beaudry and Pinsonneault (2010), whereas anxiety is a future-oriented emotional state. Anxiety is the anticipation of a possible imminent threat, that could be more fearful than a real threat (Grupe and Nitschke, 2013). Emotions can be grouped according to their valence: positive (joy, satisfaction, pleasure and excitement, hope, arousal), or negative (anger, frustration, annoyed and anxiety, fear, worry).

Finally, note that emotions in video games can be perceived as an affective loop between the expression of emotions by the player, the possible detection of emotions by the game itself, and its adaptation to the context in response to the player (Yannakakis et al., 2011). Previous investigations on emotions focused on endogenous point of view of the subject or are situated in other fields (psychology, etc.). Moreover, videogames and serious games are quite different objects. Whereas the former are for entertainment, the latter are oriented towards a serious purpose. So the relation between the subject's emotions and the serious game needs to be specifically investigated.

\section{Hypotheses}

Based on our review of the literature we have derived several hypotheses. This is to understand the correlation between the use of serious games and emotions. We postulate that ease of use has an influence on emotions, satisfaction and intention to use. Indeed, the ease of use of a system should allow the user to focus on his task as proposed by the flow theory (Csikszentmihalyi, 2008), without being disturbed by the technical problems of the system. On the opposite, a system in which use is complicated will divert the attention of the player who cannot focus on the game itself. Therefore, we propose the following hypotheses:

\begin{tabular}{|l|}
\hline Correlation between ease of use and emotions \\
\hline H1a: Perceived ease of use is positively correlated with achievement emotions (joy, satisfaction, pleasure) \\
\hline H1b: Perceived ease of use is positively correlated with challenge emotions (excitement, hope, arousal) \\
\hline H1c: Perceived ease of use is negatively correlated with loss emotions (anger, frustration, annoyed) \\
\hline H1d: Perceived ease of use is negatively correlated with deterrence emotions (Anxiety, fear, worry) \\
\hline
\end{tabular}

The multimedia quality of the serious game enhances the immersion, which is the perception of being inside and interacting with an environment that continuously provides a stream of stimuli and experience (Witmer and Singer, 1998). This is consistent with the flow commitment (Sherry, 2004). We therefore propose the following hypotheses:

\begin{tabular}{|l|}
\hline Correlation between multimedia quality and emotions \\
\hline H2a: Perceived multimedia quality is positively correlated with achievement emotions (joy, satisfaction, pleasure) \\
\hline H2b: Perceived multimedia quality is positively correlated with challenge emotions (excitement, hope, arousal) \\
\hline H2c: Perceived multimedia quality is negatively correlated with loss emotions (anger frustration, annoyed) \\
\hline H2d: Perceived multimedia quality is negatively correlated with deterrence emotions (Anxiety, fear, worry) \\
\hline
\end{tabular}

The existence of relations between ease of use, system quality (multimedia), satisfaction and intention to use had been shown by the work of Delone and McLean and numerous validations have confirmed this existence (Delone and McLean, 2003, Petter, Delone, and McLean, 2008). More recent work by Petter, Delone, and McLean (2013) on the independent variable of IS success has linked trust, confidence, and expectations to IS success. Following on this we proposed these hypotheses: 


\begin{tabular}{|l|}
\hline Correlation between ease of use and satisfaction / intention to use \\
\hline H3a: Perceived ease of use is positively correlated with satisfaction \\
\hline H3b: Perceived ease of use is positively correlated with intention to use \\
\hline Correlation between multimedia quality and emotions / intention to use \\
\hline H4a: The multimedia quality of the game is positively correlated with the satisfaction \\
\hline H4b: The multimedia quality of the game is positively correlated with the intention to use \\
\hline
\end{tabular}

The quality of the information in the Delone and Mclean model is represented there by the quality of the game content in the serious game. The latter influences satisfaction and intention to use. Game content should therefore be correlated with the emotions felt by the users (Beaudry and Pinsonneault, 2010). Joy (Kirriemuir and McFarlane, 2004, Labonte-LeMoyne et al., 2017, Nadolski et al., 2008) and flow (Csikszentmihalyi, 2008) are frequently reported in the use of serious games. Thus a quality serious game would be likely to give rise to positive emotions to the user. In other words, a high quality system should be associated with positive emotions, great satisfaction and a strong intention to use. We therefore propose the following hypotheses:

\begin{tabular}{|l|}
\hline Correlation between quality of content and emotions \\
\hline H5a: The quality of game content is positively correlated with achievement emotions (joy, satisfaction, pleasure) \\
\hline H5b: The quality of game content is positively correlated with challenge emotions (excitement, hope, arousal) \\
\hline H5c: The quality of game content is negatively correlated with loss emotions (anger frustration, annoyed) \\
\hline H5d: The quality of game content is negatively correlated with deterrence emotions (anxiety, fear, worry) \\
\hline
\end{tabular}

\section{Correlation between quality of content and satisfaction/intention to use}

H6 a: The quality of game content is positively correlated with satisfaction

$\mathrm{H} 6 \mathrm{~b}$ : The quality of game content is positively correlated with the intention to use

Satisfaction is potentially influenced by the emotions of the user, particularly by joy: " Happiness-a composite of life satisfaction, coping resources, and positive emotions-predicts desirable life outcomes in many domains" (Cohn et al., 2009, p. 361). Satisfaction is a state (Labonte-LeMoyne et al., 2017, Raybourn 2007, Zhang and Zwolinski 2015), which shows that expectations are met, that desires are met. Satisfaction can influence the intention to use the serious game (Cohard and Marciniak, 2014). Satisfaction is an essential element in the success of the serious game: positive emotions towards the serious game will lead to a better satisfaction that should be associated with a greater intention to use. This is why we make the following hypotheses:

\begin{tabular}{|l|}
\hline Correlations between emotions and satisfaction \\
\hline H7a: Achievement emotions (joy, satisfaction, pleasure) are positively correlated to satisfaction \\
\hline H7b: Challenge emotions (excitement, hope, arousal) are positively correlated to satisfaction \\
\hline H7c: Loss emotions (anger frustration, annoyed) are negatively correlated to satisfaction \\
\hline H7d: Deterrence emotions (anxiety, fear, worry) are negatively correlated to satisfaction \\
\hline
\end{tabular}

\begin{tabular}{|l|}
\hline Correlation between emotion and success of the serious game \\
\hline H8a: Achievement emotions (joy, satisfaction, pleasure) are positively correlated to success \\
\hline H8b: Challenge emotions (excitement, hope, arousal) are positively correlated to success \\
\hline H8c: Loss emotions (anger frustration, annoyed) are negatively correlated to success \\
\hline H8d: Deterrence emotions (anxiety, fear, worry) are negatively correlated to success
\end{tabular}


Correlation between satisfaction and intention to use / success

H9 a: Satisfaction is positively correlated to the intention to use

H9 b: Satisfaction is positively correlated to the success of the serious game in general

Satisfaction and intention to use (Petter, Delone and McLean, 2008), are the factors correlated to learning and perceived utility, that we have identified. We also postulate that the overall success of serious game is influenced by emotions, satisfaction and perceived user learning. Furthermore, satisfaction and intention to use contribute to individual impact, perceived usefulness and learning. Learning has a central role in serious games. In the literature the authors (Labonte-LeMoyne et al., 2017; Van der Wal et al., 2016), often stressed experiential learning and observation as preferred modes of learning in serious games (Bandura, 1977; Kolb and Kolb, 2005). High satisfaction with the serious game should be associated with greater perceived usefulness as well as better perceived learning. Positive valence emotions (Beaudry and Pinsonneault, 2010), should allow a more favourable cognitive learning context and thus promote learning. We therefore make the following hypotheses:

\begin{tabular}{|l|}
\hline Correlation between emotions and learning \\
\hline H10a: Achievement emotions (joy, satisfaction, pleasure) are positively correlated to learning \\
\hline H10b: Challenge emotions (excitement, hope, arousal) are positively correlated to learning \\
\hline H10c: Loss emotions (anger frustration, annoyed) are negatively correlated to learning \\
\hline H10d: Deterrence emotions (anxiety, fear, worry) are negatively correlated to learning \\
\hline
\end{tabular}

Correlation between satisfaction and perceived utility /learning

H 11 a: Satisfaction is positively correlated to perceived utility

H 11 b: Satisfaction is positively correlated to learning

Correlation between intention to use and perceived utility / learning

H 12 a: Intention to use is positively correlated to perceived utility

H 12 b: Intension to use is positively correlated to learning

The strong concern that appears throughout the literature for the analysis of the effectiveness of serious games, testifies to the importance of this parameter in the success of the serious game (Aydan et al., 2017, Giard and Magnant, 2013; Labonte-LeMoyne et al., 2017, Li et al., 2017, Van der Wal et al., 2016). This concern appears more generally in the field of training (HRM) and frequently passes through the Kirkpatrick model (1998). Given that learning is a central element it will be associated with the success of the serious game in general. We therefore make the following hypothesis:

Correlation between learning and the success of the serious game

$H$ 13: Learning is positively correlated to the success of the serious game in general

After presenting our research hypotheses, we implement them using a structured survey (exploratory research).

\section{Research Implementation}

We now explain the research implementation: the study population, the use of the game, the data collection and the data analysis. 


\subsection{Study population}

This research was conducted in a management school of a university. Respondents are third-year undergraduate and master's students in first and second year of management and entrepreneurship. The subjects were asked to answer to an online questionnaire (see Appendix 1). This research has been conducted following the ethical requirements established by the French national board of ethics.

\subsection{Use of the serious game}

The design of the serious game was done internally from different technologies and animation softwares. A virtual avatar explains concepts on a storytelling mode (Fig.1). Then questions appear which lead to rise to a memorization-reflection. This operating mode allows to create a dialog between the avatar and the user.

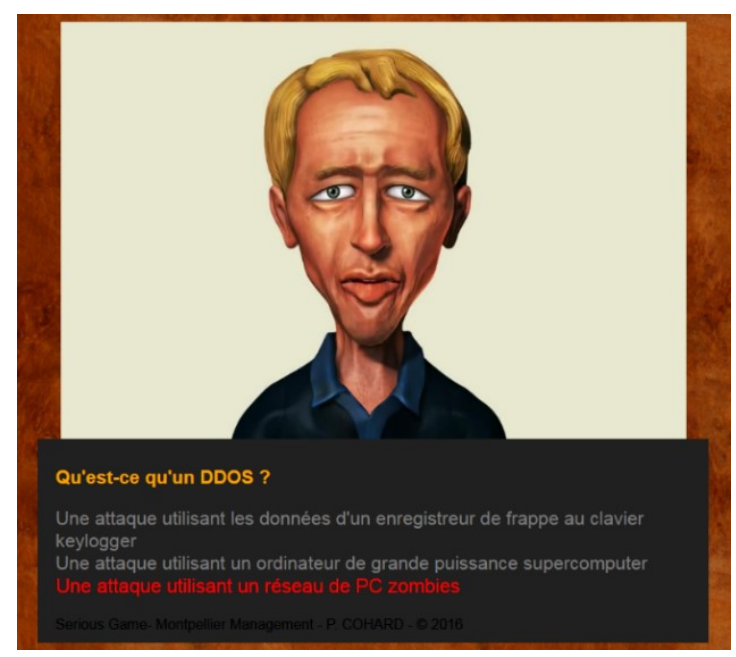

Figure 1: The serious game interface

The game is based on rule of collecting clues with which the player can answer precisely to the question. The goal is to raise questions about the security of the Information System that pushes the user to improve his score by understanding the elements and going to deepen his knowledge. Every distractor (wrong answer) gives instantly a negative feedback explaining the error. At the end of the game the final recapitulation shows every error.

\subsection{Data collection}

The sample size is $n=50$ valid responses (out of 71 responses). The respondents have a novice level of understanding about IS security concepts.

The serious game was used as follows: students are invited to use the serious game and at the end of it to answer a questionnaire. The link to the questionnaire is indicated under the score obtained by the user to encourage him to answer.

The data were collected by questionnaire between $01 / 11 / 2017$ and 20/02/2018. We used 5 point Likert scales, from strongly disagree to strongly agree. We paid particular attention to the anchor effect by placing the negative answers first, and to the halo bias by placing the general questions at the beginning of the questionnaire.

\subsection{Data analysis}

We chose to use Spearman's Rho correlation coefficient because it is less sensitive for the processing of ordinal data. Moreover, Spearman's correlation (see equation (1) below) makes it possible to detect monotonic relations (Dickinson Gibbons and Chakraborti, 2003), without presupposing on the form of the relation.

$$
R=1-\frac{6 \sum_{i=1}^{n} D_{i}^{2}}{n\left(n^{2}-1\right)}
$$


Spearman's correlation coefficient is widely used, including in the field of game and simulation (Corbeil and Laveault 2011, Petty and Barbosa 2016, Strohhecker and Größler 2015). It should be noted that the size of the sample, if it is adapted to the treatment carried out, could also constitute a limit for subsequent analyses (PLS, etc.). An increase in the sample size will be an extension of this research. The literature review allowed us to identify possible correlations that form our hypotheses. From these we analyse the correlations obtained to see if they are empirically supported.

\section{Results}

The analysis reveals significant correlations at the alpha value of 0.01 or 0.05 (identified by *). Concerning the correlation matrix, we notice the link between several elements.

The ease of use is positively correlated with satisfaction (0.618) and emotions of joy, satisfaction, pleasure (0.442), and moreover excitement, hope, enlightenment (0.432). The ease of use is also positively correlated with the intention of reusing the serious game later $\left(0.355^{*}\right)$. For this we accept the hypotheses $\mathrm{H} 1 \mathrm{a}, \mathrm{H} 1 \mathrm{~b}$, $\mathrm{H} 3 \mathrm{a}$ and $\mathrm{H} 3 \mathrm{~b}$. Note that the ease of use correlation - intention to reuse for revisions is not significant. Negative correlations expected between ease of use and loss emotions as well as deterrence emotions are not significant. We reject hypotheses $\mathrm{H} 1 \mathrm{c}$ and $\mathrm{H} 1 \mathrm{~d}$.

The multimedia quality of the game (game multimedia quality) is positively correlated with satisfaction (0.370), emotions of excitement, hope, awakening (0.409) and emotions of joy, satisfaction, pleasure $(0.315 *)$. It is also positively correlated with the intention of reusing the serious game later $\left(0.343^{*}\right)$. This is why we accept the hypotheses $\mathrm{H} 2 \mathrm{a}, \mathrm{H} 2 \mathrm{~b}, \mathrm{H} 4 \mathrm{a}$ and $\mathrm{H} 4 \mathrm{~b}$. Please also note that the ease of use correlation - intention to reuse for revisions is not significant. Negative correlations expected between multimedia quality and loss emotions as well as emotions are not significant. We therefore reject the hypotheses $\mathrm{H} 2 \mathrm{c}$ and $\mathrm{H} 2 \mathrm{~d}$.

The quality of the content of the game (game content quality) is positively associated with the intention to use $(0.386)$ including during revisions $\left(0.359^{*}\right)$, to the satisfaction $(0.523)$ and to the emotions of joy, satisfaction, pleasure (0.612) as well as excitement, hope, enlightenment (0.463). Game content quality is negatively related to emotions of disappointment, frustration and annoyance $(-0.370)$. Therefore, we accept the hypotheses $\mathrm{H} 5 \mathrm{a}, \mathrm{H} 5 \mathrm{~b}, \mathrm{H} 5 \mathrm{c}, \mathrm{H} 6 \mathrm{a}$ and $\mathrm{H} 6 \mathrm{~b}$. The expected negative correlation between quality of game content and the deterrence emotions is not significant. So that we reject the hypothesis $\mathrm{H} 5 \mathrm{~d}$.

The emotions of joy, satisfaction, pleasure (0.643) as well as excitement, hope, enlightenment (0.571) are positively correlated to the success of the serious game (overall score) and satisfaction (respectively 0.574 and 0.569). This leads us to accept the hypotheses $\mathrm{H7a}, \mathrm{H7b}, \mathrm{H} 8 \mathrm{a}$ and $\mathrm{H} 8 \mathrm{~b}$. Concerning the negative correlations expected in connection with the emotions, the loss emotions only are negatively related to the success (0.328 *). For this we accept the hypothesis $\mathrm{H} 7 \mathrm{c}$ and reject hypotheses $\mathrm{H} 7 \mathrm{~d}, \mathrm{H} 8 \mathrm{c}$ and $\mathrm{H} 8 \mathrm{~d}$.

We notice that emotions are related to learning, joy, satisfaction, pleasure (0.403) as well as excitement, hope, enlightenment (0.377). We also note that emotions of disappointment, frustration and annoyance are negatively related to perceived utility $(-0.472)$ and learning - attitudinal change $(-0.364)$. So that we accept the following hypotheses $\mathrm{H} 10 \mathrm{a}, \mathrm{H} 10 \mathrm{~b}, \mathrm{H} 10 \mathrm{c}$. The negative correlation between deterrence emotions and learning is not significant, so we reject $\mathrm{H} 10 \mathrm{~d}$.

Satisfaction is positively correlated with intention to use (0.485), perceived utility (0.552), learning (0.476), and the success of the serious game (0.580). So we accept the hypotheses H9a, H9b, H11a and H11b.

The intention to use (later) is positively correlated with perceived utility (0.512) and is also related to perceived learning $\left(0.337^{*}\right.$ ) (attitudinal $0.321^{*}$ ). Hypotheses $\mathrm{H} 12 \mathrm{a}$ and $\mathrm{H} 12 \mathrm{~b}$ are therefore accepted. Eventually, the perceived learning (0.595) (attitudinal 0.376) is positively correlated with the success of the serious game in general. Thus the hypothesis $\mathrm{H} 13$ is accepted.

The correlation matrix is presented below (Table 1). 
Table 1: Correlation Matrix

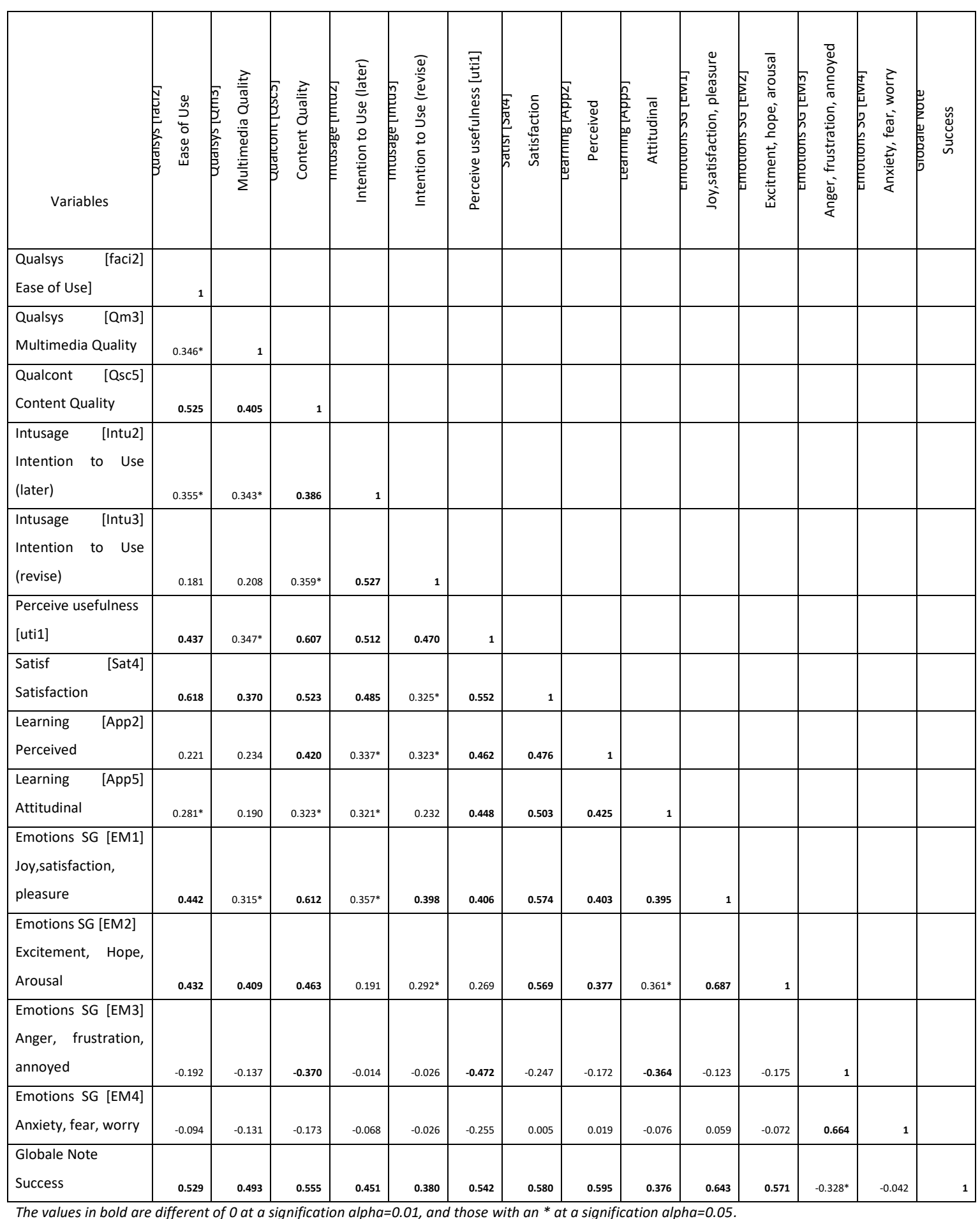

Accepted and rejected hypotheses are summarized in the table in Appendix 2.

\section{Discussion}

In our research we studied the following question: What is the place of emotions in the user experience of serious game? We have shown that the various factors are found empirically, by Spearman's correlation, according to our hypotheses except for the negative correlations of the loss and deterrence emotions. This indicates the importance of achievement and challenge emotions, which was expected. However, it also shows that negative emotions are not a total restrain in this kind of program. That's in accordance with the need to 
live a flow experience (Csikszentmihalyi, 2008). Moreover, the flow experience is formed of several dimensions that opens up prospects for research.

In this serious game a virtual avatar explains concepts in a storytelling mode, then questions appear which gives rise to a memorization-reflection. The goal is to raise questions about the security of the IS that pushes the user to improve his score by understanding the elements, changing his representations and going to deepen his knowledge. Our research shows that the use of serious game in a context of student training leads to a high level of overall success (mean of the Success ratings: 7.3 / 10, standard deviation: 1.69). This indicates that the design must take into account the user need as suggested by Norman (2013). The use of real-time 3D (Aydan et al., 2017, Li et al., 2017) is not necessary in all projects. Indeed, in this one it is unnecessary.

In the sample, the age of the users of the serious game is mainly between 20 and 25 . This variable is in fact controlled by the kind of respondent. Further investigations may be carried out to check the impact of age on the interest in serious games. This is a trail for future research. Moreover, learning is a key concept of the serious game, as we have shown: learning is correlated to the overall success of the serious game (H13). This is consistent with the work of the field (Labonte-LeMoyne et al., 2017, Landers 2014, Van der Wal et al., 2016).

Our study confirms the influence of the multimedia quality of the game (game design), its ease of use and the quality of the content of the game $(\mathrm{H} 1$ to $\mathrm{H} 4)$. But this research also shows how emotions can influence both satisfaction and success ( $\mathrm{H} 7$ and $\mathrm{H} 8$ ). This is in correspondence with the literature on flow (Csikszentmihalyi, 2008, Kirriemuir and McFarlane, 2004) and that on emotions related to IS (Beaudry and Pinsonneault, 2010). The detected correlations between the considered variables constitute a theoretical contribution of our research. This allows to answer our research question: What is the place of emotions in the user experience of serious game? The link between the success of the serious game and the emotions plays an important role: joy, satisfaction, and pleasure (0.403) are the mainsprings on which the serious game is based. But these are coupled with excitement, hope, enlightenment $(0.377)$ that helps to maintain attention. This seems consistent with the work of Cohn et al. (2009), on the ability to adapt to the changing environment. Maybe these last emotions are related to the engagement of the players. Deception, frustration and annoyance are negatively linked with satisfaction and learning, which shows their deleterious side in the user experience. Yet the overcoming of the frustration of failure in the game could be likened to dimensions of the flow (achievable challenge). Everything should be done not to turn the player down by placing him in a state of anxiety.

Satisfaction is an important factor produced by the use of the serious game. Note that satisfaction is positively linked to perceived usefulness, ease of use and quality of content, what is consistent with the work of Petter, Delone and McLean $(2008,2013)$. In the light of our results these dimensions can influence the success of the serious game via the satisfaction variable. These perceptions, through the characteristics of the game are factors of flow (Csikszentmihalyi, 2008, Kirriemuir and McFarlane, 2004). Furthermore, satisfaction is directly related to the quality of the training provided. Indeed, the evaluation model of Kirkpatrick (1998) indicated that the first level to evaluate training is the satisfaction of the learners. Other dimensions of this model could be integrated in our analyses like objective learning or organisational results which opens other avenues for the extension of this research.

\section{Conclusion}

This research focuses on the multiple factors of serious games and the implications of emotions in them. We have shown through a review of the literature and a statistical analysis of 50 respondents, that the quality components of the multimedia system and quality of the content of the serious game are correlated with the achievements and challenge emotions and that these emotions are correlated with satisfaction, learning and the success of the serious game. We have also shown that loss emotions such as frustration and disappointment have a negative impact on the success and the satisfaction of the serious game. All these factors that have been identified as correlated are potential control levers. They affect the perception and emotions of the user and their understanding could improve serious games. The hypotheses proposed are based on the domain literature. Statistical analysis shows the validity of certain correlations. This research improves the understanding of the implication of emotions when using serious games. Future research will be undertaken to propose a research model to show causalities between variables. This will allow to test the existence of potential moderator variables, introduce new variables of interest and understand more deeply the interactions and roles of these variables. This will help to better understand the effects of serious games 
on the user. These new variables can relate to the characteristics of the game or the user himself. In future research, we should also test this serious game in a professional environment.

\section{References}

Alvarez, J., 2007. Du jeu vidéo au Serious Game, Approches culturelle, pragmatique et formelle. PhD. University of Toulouse.

Aydan, U., Yilmaz, M., Clarke, P., and O'Connor, R., 2017. Teaching ISO/IEC 12207 software lifecycle processes: a serious game approach. Computer Standards and Interfaces, 54(1), pp.129-138.

Bandura, A., 1977. Self-efficacity: toward a unifying theory of behavioral change. Psychological Review, 84(2), pp.191-215.

Beaudry, A., and Pinsonneault, A., 2010. The other side of acceptance: studying the direct and indirect effects of emotions on information technology use. MIS Quarterly, 34(4), pp.689-710.

Chou, C.C., Jeng, A.P., Chu, C.P., Chang, C.H. and Wang, R.G., 2018. Generation and visualization of earthquake drill scripts for first responders using ontology and serious game platforms, Advanced Engineering Informatics, 38(1), pp. 538-554.

Cohard, P., and Marciniak, R., 2014. Nursing homes as a case for assessing Serious Games. Systèmes d'information et management, 19(3), pp.69-96.

Cohn, M. A., Fredrickson, B. L., Brown, S. L., Mikels, J. A., and Conway, A. M., 2009. Happiness unpacked: positive emotions increase life satisfaction by building resilience. Emotion, 9(3), pp.361-368.

Corbeil, P., and Laveault, D., 2011. Validity of a simulation game as a method for history teaching. Simulation and Gaming, 42(4), pp.462-475.

Csíkszentmihalyi, M., 1988. Optimal experience: psychological studies of flow in consciousness. Cambridge: Cambridge University Press.

Csikszentmihalyi, M., 2008. Flow, the psychology of optimal experience. New York: First Harper Perennial modern classic.

de Manzano, Ö., Theorell, T., Harmat, L., and Ullén, F., 2010. The psychophysiology of flow during piano playing. Emotion, 10(3), pp.301-311.

Delone, W., and McLean, E., 2003. The DeLone and McLean model of information systems Success: a ten-year update. Journal of Management Information Systems, 19(4), pp.9-30.

Dickinson Gibbons, J., and Chakraborti, S., 2003. Nonparametric statistical inference. New York: Marcel Dekker .

Ekman, P., 1992. An argument for basic emotions. Cognition and Emotion, 1(6), pp.169-200.

Ekman, P., 1999. Basic emotions. In T. Dalgleish and M. Power, ed. 1999, Handbook of cognition and emotion. Chichester: Wiley. pp.45-60.

Erhel, S., and Jamet, E., 2013. Digital game-based learning: impact of instructions and feedback on motivation and learning effectiveness. Computer and Education, 67(1), pp.156-167.

Feldman-Barrett, L., and Russell, J.,1998. Independence and bipolarity in the structure of affect. Journal of Personality and Social Psychology, 74(1), pp.967-984.

Garris, R., Ahlers, R., and Driskell, J. E., 2002. Games, motivation, and learning: a research and practice model. Simulation and Gaming, 33(4), pp.441-467.

Giard, C., and Magnant, A., 2013. Serious games as new educational tools: how effective are they? A meta-analysis of recent studies. Journal of Computer Assisted Learning, 29(1), pp.207-219.

Grupe, W., and Nitschke, J., 2013. Uncertainty and anticipation in anxiety: an integrated neurobiological and psychological perspective. Nature Reviews Neuroscience, 7(1), pp.488-501.

Guillén-Nieto, V., and Aleson-Carbonell, M., 2012. Serious games and learning effectiveness: The case of It's a Deal! Computers and Education, 58(1), pp.435-448.

Ketter, W., Peters, M., Collins, J., and Gupta, A., 2016. A multiagent competitive gaming platform to address societal challenges. MIS Quarterly, 40(2), pp.447.

Kirkpatrick, D. L., 1998. Evaluating training programs, the four levels. San Francisco: Berrett-Koehler Publishers.

Kirriemuir, J., and McFarlane, A., 2004. Literature review in games and learning. (Report No.8). Bristol: Futurelab.

Kolb, A., and Kolb, D., 2005. Learning styles and learning spaces: enhancing experiential learning in Higher Education. Academy of Management Learning and Education, (4), pp.193-212.

Labonte-LeMoyne, E., Leger, P.M., Robert, J., Babin, G., Charland, P., and Michon, J.F., 2017. Business intelligence serious game participatory development: lessons from ERPsim for big data. Business Process Management Journal, 23(3), pp.493-505.

Landers, R. N., 2014. Developing a theory of gamified learning: linking serious games and gamification of learning. Simulation and Gaming, 45(6), pp.752-768.

Li, K., Hall, M., Bermell-Garcia, P., Alcock, J., Tiwari, A., and González-Franco, M., 2017. Measuring the learning effectiveness of serious gaming for training of complex manufacturing tasks. Simulation and Gaming, 48(6), pp.770-790.

Lichtlé, M.C., and Plichon, V., 2014. Les émotions ressenties dans un point de vente : proposition d'une échelle de mesure. Recherche et Applications en Marketing, 29(1), pp.3-26.

Loerzel, V., Clochesy, J., and Geddie, P., 2018. Using a community advisory board to develop a serious game for older adults undergoing treatment for cancer. Applied Nursing Research, 39(1), pp.207-210. 
Malone, T., 1981. Toward a theory of intrinsically motivating instruction. Cognitive Science, 1(4), pp.334-369.

Malone, T., and Lepper, M., 1987. Making learning fun: a taxonomy of intrinsic motivations for learning. In: R. Snow and J. Farr, ed. 1987. Aptitude, learning and instruction III: Conative and affective process analyses. Hillsdale: Erlbaum. pp. 233-253.

Matallaoui A., Herzig P. and Zarnekow R., 2015. Model-driven serious game development integration of the gamification modeling language gaml with unity. 2015 48th Hawaii International Conference on System Sciences, IEEE, pp. 643-651.

Nadolski, R., Hummel, H., Van Den Brink, H., Hoefakker, R., Slootmaker, A., Kurvers, H., and Storm, J., 2008. EMERGO: methodology and toolkit for efficient development of serious games in higher education. Simulation and Gaming, 3(39), pp.338-352.

Norman, D. A., 2013. The design of everyday things. New York: Basic Books.

Perez-Estrada, L. E., Groen, D., and Ramirez-Marquez, J. E., 2017. A serious video game to support decision making on refugee aid deployment policy. Procedia Computer Science, 108(1), pp.205-214.

Petter, S., Delone, W., and McLean, E., 2008. Measuring information systems success: models, dimensions, measures and interrelationships. European Journal of Information Systems, (17), pp.236- 263.

Petter, S., DeLone, W., and McLean, E. R., 2013. Information Systems success: the quest for the independent variables. Journal of Management Information Systems, 29(4), pp.7-62.

Petty, M. D., and Barbosa, S. E., 2016. Improving air combat maneuvering skills through self-study and simulation-based practice. Simulation and Gaming, 47(1), pp.103-129.

Quinn, C. A., Rollock, D., and Vrana, S. R., 2014. A test of Spielberger's state-trait theory of anger with adolescents: five hypotheses. Emotion, 14(1), pp.74-84.

Raybourn, E. M., 2007. Applying simulation experience design methods to creating serious game-based adaptive training systems. Interacting with Computers. 19(2), pp.206-214.

Russell, J., 1980. A circumplex model of affect. Journal of Personality and Social Psychhology, 39(6), pp.1161-1178.

Sherry, J., 2004. Flow and media enjoyment. Communication Theory, 14(4), pp.328-347.

Strohhecker, J., and Größler, A., 2015. Performance in tangible and in cognitive stock-flow tasks: closer than expected. Simulation and Gaming, 46(3-4), pp.230-254.

Thompson, D., Baranowski, T., Griffith, M., Buday, R., Baranowski, J., Thompson, V., and Jago, R., 2010. Serious video games for health: how behavioral science guided the development of a serious video game. Simulation and Gaming, 41(4), pp.587-606.

Van der Wal, M., de Kraker, J., Kroeze, C., and Kirschner, P., 2016. Can computer models be used for social learning? A serious game in water management. Environmental Modelling and Software, 75(1), pp.119-132.

Witmer, B., and Singer, M., 1998. Measuring presence in virtual environment: a presence questionnaire. Presence, 7(3), pp.225-240.

Yannakakis, G., Karpouzis, K., Paiva, A., and Hudlicka, E., 2011. Emotion in games. Affective Computing and Intelligent Interaction, (1), pp.497.

Zhang, F., and Zwolinski, P., 2015. SimGreen: a serious game to learn how to improve environmental integration into companies. In S. Kara, ed. 2015. The 22nd CIRP Conference on Life Cycle Engineering. Sydney: Procedia CIRP 29. pp.281-286.

Zyda, M., 2005. From visual simulation to virtual reality to games. IEEE Computer Society, 38(9), pp.25-32. 
Appendix- 1: Items

\begin{tabular}{|c|c|}
\hline Variables & Items \\
\hline $\begin{array}{l}\text { Qualsys[faci2] } \\
\text { Ease of Use }\end{array}$ & I think the serious game is easy to use \\
\hline $\begin{array}{l}\text { Qualsys[Qm3] } \\
\text { Multimedia Quality }\end{array}$ & Learning to use the serious game was easy for me \\
\hline $\begin{array}{l}\text { Qualcont[Qsc5] } \\
\text { Content Quality }\end{array}$ & The content of the serious game is interesting \\
\hline $\begin{array}{l}\text { Intusage[Intu2] } \\
\text { Intention to Use (later) }\end{array}$ & I want to reuse the serious game later \\
\hline $\begin{array}{l}\text { Intusage[Intu3] } \\
\text { Intention to Use (revise) }\end{array}$ & I want to reuse the serious game during my revisions \\
\hline Perceive usefulness[uti1] & The use of the serious game is useful as part of my training \\
\hline $\begin{array}{l}\text { Satisf[Sat4] } \\
\text { Satisfaction }\end{array}$ & $\begin{array}{l}\text { I am generally satisfied with the Serious Game on the IS } \\
\text { security }\end{array}$ \\
\hline $\begin{array}{l}\text { Learning[App2] } \\
\text { Perceived }\end{array}$ & $\begin{array}{l}\text { After using the serious game I am more attentive to the } \\
\text { security problems of the IS }\end{array}$ \\
\hline $\begin{array}{l}\text { Learning[App5] } \\
\text { Attitudinal }\end{array}$ & $\begin{array}{l}\text { After using the serious game I will be more careful when using } \\
\text { the IS }\end{array}$ \\
\hline $\begin{array}{l}\text { Emotions SG[EM1] } \\
\text { Joy, satisfaction, pleasure }\end{array}$ & $\begin{array}{l}\text { When using the serious game you felt: Joy, satisfaction, } \\
\text { pleasure }\end{array}$ \\
\hline $\begin{array}{l}\text { Emotions SG [EM2] } \\
\text { Excitement, Hope, Arousal }\end{array}$ & $\begin{array}{l}\text { when using the serious game you felt: excitement, hope, } \\
\text { arousal }\end{array}$ \\
\hline $\begin{array}{l}\text { Emotions SG [EM3] } \\
\text { Anger, frustration, annoyed }\end{array}$ & $\begin{array}{l}\text { when using the serious game you felt: anger, frustration, } \\
\text { annoyed }\end{array}$ \\
\hline $\begin{array}{l}\text { Emotions SG [EM4] } \\
\text { Anxiety, fear, worry }\end{array}$ & when using the serious game you felt: anxiety, fear, worry \\
\hline $\begin{array}{l}\text { Globale Note } \\
\text { Success }\end{array}$ & Give a global rating to the Serious Game Security of the IS \\
\hline
\end{tabular}

\section{Appendix- 2: Hypotheses}

\begin{tabular}{|l|c|}
\hline \multicolumn{1}{|c|}{ Hypotheses } & Result \\
\hline $\begin{array}{l}\text { H1a: Perceived ease of use is positively correlated with achievement emotions (joy, satisfaction, } \\
\text { pleasure) }\end{array}$ & Accept \\
\hline $\begin{array}{l}\text { H1b: Perceived ease of use is positively correlated with challenge emotions (excitement, hope, } \\
\text { arousal) }\end{array}$ & Accept \\
\hline $\begin{array}{l}\text { H1c: Perceived ease of use is negatively correlated with loss emotions (anger frustration, } \\
\text { annoyed) }\end{array}$ & Reject \\
\hline $\begin{array}{l}\text { H1d: Perceived ease of use is negatively correlated with deterrence emotions (anxiety, fear, } \\
\text { worry) }\end{array}$ & Reject \\
\hline $\begin{array}{l}\text { H2a: Perceived multimedia quality is positively correlated with achievement emotions (joy, } \\
\text { satisfaction, pleasure) }\end{array}$ & Accept \\
\hline $\begin{array}{l}\text { H2b: Perceived multimedia quality is positively correlated with challenge emotions (excitement, } \\
\text { hope, arousal) }\end{array}$ & Accept \\
\hline $\begin{array}{l}\text { H2c: Perceived multimedia quality is negatively correlated with loss emotions (anger, frustration, } \\
\text { annoyed) }\end{array}$ & Reject \\
\hline $\begin{array}{l}\text { H2d: Perceived multimedia quality is negatively correlated with deterrence emotions (anxiety, } \\
\text { fear, worry }\end{array}$ & Reject \\
\hline $\begin{array}{l}\text { H3a: Perceived ease of use is positively correlated with satisfaction } \\
\text { H3b: Perceived ease of use is positively correlated with intention to use }\end{array}$ & Accept \\
\hline $\begin{array}{l}\text { H4a: The multimedia quality of the game is positively correlated with the satisfaction } \\
\text { H4b: The multimedia quality of the game is positively correlated with the intention to use }\end{array}$ & Accept \\
\hline $\begin{array}{l}\text { H5a: } \text { The quality of game content is positively correlated with achievement emotions (joy, } \\
\text { satisfaction, pleasure) }\end{array}$ & Accept \\
\hline H5b: The quality of the game content is positively correlated with challenge emotions & Accept \\
\hline
\end{tabular}




\begin{tabular}{|c|c|}
\hline Hypotheses & Result \\
\hline \multicolumn{2}{|l|}{ (excitement, hope, arousal) } \\
\hline $\begin{array}{l}\text { H5c: The quality of game content is negatively correlated with loss emotions (anger, frustration, } \\
\text { annoyed) }\end{array}$ & Accept \\
\hline $\begin{array}{l}\text { H5d: The quality of game content is negatively correlated with deterrence emotions (anxiety, } \\
\text { fear, worry) }\end{array}$ & Reject \\
\hline H6 a: The quality of game content is positively correlated with satisfaction & Accept \\
\hline H6 b: The quality of game content is positively correlated with the intention to use & Accept \\
\hline H7a: Achievement emotions (joy, satisfaction, pleasure) are positively correlated to satisfaction & Accept \\
\hline H7b: Challenge emotions (excitement, hope, arousal) are positively correlated to satisfaction & Accept \\
\hline H7c: Loss emotions (anger, frustration, annoyed) are negatively correlated to satisfaction & Accept \\
\hline H7d: Deterrence emotions (anxiety, fear, worry) are negatively correlated to satisfaction & Reject \\
\hline H8a: Achievement emotions (joy, satisfaction, pleasure) are positively correlated to success & Accept \\
\hline H8b: Challenge emotions (excitement, hope, arousal) are positively correlated to success & Accept \\
\hline H8c: Loss emotions (anger, frustration, annoyed) are negatively correlated to success & Reject \\
\hline H8d: Deterrence emotions (anxiety, fear, worry) are negatively correlated to success & Reject \\
\hline H9 a: Satisfaction is positively correlated to the intention to use & Accept \\
\hline H9 b: Satisfaction is positively correlated to the success of the serious game in general & Accept \\
\hline H10a: Achievement emotions (joy, satisfaction, pleasure) are positively correlated to learning & Accept \\
\hline H10b: Challenge emotions (excitement, hope, arousal) are positively correlated to learning & Accept \\
\hline H10c: Loss emotions (anger, frustration, annoyed) are negatively correlated to learning & Accept \\
\hline H10d: Deterrence emotions (anxiety, fear, worry) are negatively correlated to learning & Reject \\
\hline H 11 a: Satisfaction is positively correlated to perceived utility & Accept \\
\hline H 11 b: Satisfaction is positively correlated to learning & Accept \\
\hline H 12 a: Intention to use is positively correlated to perceived utility & Accept \\
\hline H 12 b: Intension to use is positively correlated to learning & Accept \\
\hline H 13: Learning is positively correlated to the success of the serious game in general & Accept \\
\hline
\end{tabular}

